\title{
Measurement of dairy calf behavior prior to onset of clinical disease and in response to disbudding using automated calf feeders and accelerometers
}

\author{
M. A. Sutherland, ${ }^{* 1}$ G. L. Lowe,${ }^{*}$ F. J. Huddart, ${ }^{*}$ J. R. Waas, $\dagger$ and M. Stewart ${ }^{\star 2}$ \\ ${ }^{*}$ AgResearch Ltd., Ruakura Research Centre, Hamilton 3214, New Zealand \\ †School of Science, The University of Waikato, Private Bag 3105, Hamilton, New Zealand
}

\begin{abstract}
We determined if feeding and lying behavior, recorded by automatic calf feeding systems (ACFS) and accelerometers, could be used to detect changes in behavior before onset of neonatal calf diarrhea (NCD) or in response to disbudding pain in dairy calves. At $4 \mathrm{~d}$ of age, 112 calves had accelerometers attached to their hind leg and were housed in pens with ACFS. Calves were examined daily for signs of illness or injury. Of the 112 calves monitored, 18 were diagnosed with NCD; activities of calves with NCD were then compared with those of 18 healthy controls (calves that had no symptoms of NCD, other illnesses, or injury). Feeding (milk consumption and the number of rewarded and unrewarded visits to the feeder) and lying behavior during the $5 \mathrm{~d}$ leading up to calves displaying clinical signs of NCD were analyzed. Calves with NCD performed fewer unrewarded visits and consumed less milk than healthy calves during the 2- and 4-d periods before diagnosis with NCD, respectively. Calves with NCD tended to perform fewer lying bouts than healthy calves over the 5 -d period before diagnosis with NCD. At 3 wk of age, a subset of 51 healthy calves were allocated to 1 of 5 treatment groups: (1) sham handling (SHAM, $\mathrm{n}=10$ ), (2) cautery disbudding $(\mathrm{DB}, \mathrm{n}=11),(3)$ administration of local anesthetic (LA) and $\mathrm{DB}(\mathrm{LA}+\mathrm{DB}, \mathrm{n}=11), 4)$ administration of a nonsteroidal anti-inflammatory drug (NSAID) and DB (NSAID+DB, $\mathrm{n}=9$ ), and (5) administration of LA, NSAID and DB $(\mathrm{LA}+\mathrm{NSAID}+\mathrm{DB}, \mathrm{n}=10)$. Feeding and lying behavior were recorded continuously for $24 \mathrm{~h}$ pre- and postdisbudding. We found no effect of treatment on the number of rewarded or unrewarded
\end{abstract}

\footnotetext{
Received November 27, 2017.

Accepted May 4, 2018.

${ }^{1}$ Corresponding author: mhairi.sutherland@agresearch.co.nz

${ }^{2}$ Present address: Greyhound Racing New Zealand, TAB Building, Lower Hutt 5012, Wellington, New Zealand.
}

visits to the feeder and milk volume consumed $24 \mathrm{~h}$ before administration of treatments. During the 24-h postdisbudding period, SHAM calves performed more unrewarded visits than $\mathrm{DB}, \mathrm{LA}+\mathrm{DB}$, and $\mathrm{NSAID}+\mathrm{DB}$ calves, but the number of unrewarded visits did not differ between SHAM and LA+NSAID+DB calves. During the first hour of the posttreatment period we noted a difference in lying times among treatments, with DB and NSAID+DB calves spending less time lying than SHAM calves and lying times being similar between SHAM, LA+DB, and LA+NSAID+DB calves. The ACFS and accelerometers have the potential to automatically gather valuable information regarding health status and pain in calves. Therefore, it may be advantageous to combine both of these measures (ACFS and accelerometers) when evaluating NCD on farm or pain in calves in future research.

Key words: behavior, disbudding, feeding, automated measures, welfare

\section{INTRODUCTION}

Automated techniques for measuring individual calf behavior on-farm are now available; feeding behavior can be detected remotely with automatic calf feeding systems (ACFS; Svensson and Jensen, 2007; Borderas et al., 2009) and activity can be recorded using accelerometers (e.g., Hobo data loggers; Bonk et al., 2013). Automated systems have the advantage of collecting data noninvasively with reduced labor input. Feeding and lying behavior have been shown to change in response to sickness (Svensson and Jensen, 2007; Borderas et al., 2008; Szyszka and Kyriazakis, 2013) and pain (Graf and Senn, 1999; Heinrich et al., 2010) in calves. Hence, automated measures of feeding and lying behavior could potentially be used to detect early signs of disease and pain in calves.

Neonatal calf diarrhea (NCD) is an enteric disease that is associated with severe diarrhea. Once an animal displays clinical signs of NCD, much of the associated tissue damage to the intestinal submuscosa has already 
occurred (Schroeder et al., 2012); therefore, early detection of NCD would enable calves to be promptly treated and moved to sick pens thereby reducing tissue damage and risk of disease transmission to other calves. Previous studies using ACFS and accelerometers have reported changes in feeding (Svensson and Jensen, 2007; Borderas et al., 2009; Lowe et al., 2016) and lying behavior (Swartz et al., 2017) in response to NCD and respiratory disease. However, those studies predominantly focused on changes in behavior once calves became clinically ill or the time period just prior (Svensson and Jensen, 2007; Borderas et al., 2009), or calves that were diagnosed with respiratory disease (Swartz et al., 2017). To our knowledge, no studies have measured changes in feeding in conjunction with lying behavior in calves before diagnosis with NCD. It would be valuable to measure changes in feeding and lying behavior concurrently, several days before calves become clinically ill, to assess if information collected from ACFS and accelerometers could be used for early detection of NCD on-farm.

In the United States, $94 \%$ of dairy cattle producers routinely dehorn their cattle and of these $70 \%$ disbud using cautery (USDA, 2018). Disbudding is often performed without pain relief; however, studies have shown that this procedure causes behavioral changes indicative of pain (reviewed by Stafford and Mellor, 2011). For example, calves spent less time feeding and more time lying after being cautery disbudded than sham-handled controls (Graf and Senn, 1999; Faulkner and Weary, 2000). Therefore, a need exists to evaluate different pain-mitigation strategies to alleviate the pain caused by disbudding; to do this, however, laborintensive behavioral studies are often needed. It would be useful if automated measures of feeding and lying behavior were sensitive enough to detect behavioral changes in calves in response to a painful procedure such as disbudding. Automated measures of feeding and lying behavior could then be used as a research tool to evaluate different pain-mitigation strategies for painful husbandry procedures in calves.

Disease and pain can negatively affect calf welfare, but these states are often difficult to detect and time-consuming to assess objectively. Information on feeding and lying behavior collected from ACFS and accelerometers could potentially be measured remotely on-farm and used by producers as a tool to help detect NCD early so that strategies could be promptly implemented to reduce the negative effects of this disease on calf health and production. In addition, automated measures of feeding and lying behavior could provide a useful and less labor-intensive research tool to evaluate different pain-mitigation strategies in calves. Therefore, the objectives of our study were to determine if behav- ioral data collected from ACFS and accelerometer data loggers could be used to detect changes in behavior before the onset of NCD or in response to disbudding pain in dairy calves.

\section{MATERIALS AND METHODS}

\section{Animals, Housing, and Feeding}

Our study was conducted between July and October 2014 on AgResearch's Tokanui Dairy Research Farm in South Waikato, New Zealand $\left(175^{\circ} 1800^{\prime}\right.$ E longitude, $-38^{\circ} 0300^{\prime} \mathrm{S}$ latitude). All procedures involving animals were approved by the Ruakura Animal Ethics Committee (no. 13283) under the New Zealand Animal Welfare Act 1999 (Ministry of Primary Industries, 2017).

Seventy-one Friesian dairy calves $(\mathrm{n}=71$ females) and 41 Friesian-Hereford cross calves ( $\mathrm{n}=18$ females, $\mathrm{n}$ $=23$ males) were monitored in this study. Calves were allocated to 1 of 4 pens $(\mathrm{n}=30,28,27$ and 27 calves/ pen respectively) at $4 \mathrm{~d}$ of age according to their order of birth. One pen was filled at a time, which ensured pen mates were all of similar size and stage of development. All calves were monitored to obtain a sample of animals displaying clinical signs of NCD (as described below); a subset of 51 calves that never displayed signs of NCD or other health issues or injuries were used in the pain-assessment study.

Calves were separated from their dams within $24 \mathrm{~h}$ of birth and transported to the calf-rearing facility. Upon arrival at the facility, all calves were weighed and individually identified using numbered (Allflex, Irving, TX) and electronic identification ear tags (Allflex) placed in the left and right ears, respectively. At this time accelerometers were attached to the lateral side of the hind leg (as described below).

The calf-rearing facility had a roof, solid dirt floors, and walls on all 4 sides. Calves were housed in 2 indoor pens $(8.85 \times 7.45 \mathrm{~m})$, located inside the calf rearing facility, with floors covered in wood chip bedding and post and rail fencing.

Each pen contained an ACFS, 3 water troughs, a hay feeder, and 2 meal feeders attached to the side of the pen. Water, meal (Calf-pro1 20\%, Seales Winslow, Morrinsville, New Zealand), and hay were provided ad libitum. All calves were trained over a 3 - to 4 -d period to use the ACFS from d 1 of the trial.

Trained staff performed daily health checks to assess the calves' general health and to identify calves with signs of illness. A standard operating procedure developed in conjunction with a veterinarian was used. Health checks assessed calves for the presence of diarrhea, high rectal temperatures $\left(39.5^{\circ} \mathrm{C}\right.$ or higher $)$, signs of dehydration (sunken eyes, or poor skin elasticity- 
assessed using the skin tent test), coat condition (shiny and smooth vs. dry and rough), position of the ears (erect vs. droopy), gut fill (full vs. empty stomachs), signs of navel ill (inflammation, swelling, or discharge from the navel), nasal or ocular discharge, swelling, abscesses, and injury. Trained staff were also asked to comment if calves were coughing, had crackly breaths, or were breathing fast. In the present study, calves were diagnosed as having NCD when they presented with diarrhea and high rectal temperatures $\left(39.5^{\circ} \mathrm{C}\right.$ or higher). A calf was considered to have diarrhea if it was observed passing feces with a loose to watery consistency and strong odor. For calves suspected of having diarrhea due to the presence of loose fecal matter on the top of the tail or hind legs, a fecal sample was taken to evaluate fecal consistency and to confirm whether or not that particular calf was diarrheic. Only data collected from calves diagnosed as having NCD were considered as sick calves for further analysis. Once calves exhibited signs of NCD, blood and fecal samples were collected for analysis to verify etiology of the disease. It is possible that any of the calves could have been experiencing subclinical disease during the course of the study, but it was beyond the scope of this study to test all animals for the presence of subclinical diseases; hence, animals were categorized as sick or healthy based on clinical signs of illness only. Calf BW was recorded weekly.

\section{Automated Assessment of Calf Health}

Of the 112 calves that were monitored, only data from a subset of 36 calves $[\mathrm{n}=18$ diagnosed with $\mathrm{NCD}$ $(\mathrm{BW}=41.5 \pm 6.78 \mathrm{~kg}$, mean $\pm \mathrm{SD})$ and $\mathrm{n}=18$ healthy calves $(\mathrm{BW}=41.0 \pm 5.86 \mathrm{~kg})]$ were used in this component of the study $(\mathrm{n}=6$ calves from group $1, \mathrm{n}=$ 8 calves from group 2 , and $\mathrm{n}=22$ calves from group $4 ; \mathrm{n}=24$ females and $\mathrm{n}=12$ males). Each calf with NCD was matched with a healthy calf that was from the same group, was the same breed, and was approximately the same date of birth and birth weight as the calves with NCD. A calf was considered healthy if during the course of the study it presented no symptoms of NCD or other signs of illness or injury (e.g., coughing, rectal temperatures greater than $39.5^{\circ} \mathrm{C}$, navel ill, nasal or ocular discharge, swelling or abscesses, and so on, as defined in the daily health check standard operating procedure above).

Upon completion of the trial for the first 2 groups, the experimental pens were cleaned in preparation for the final replicates (groups 3 and 4), which involved removing and replacing the top layer of woodchip with fresh wood chips. In addition, all surfaces were thoroughly sprayed using a broad-spectrum disinfectant
(Halamid, Axcentive SARL; Bouc-Bel-Air, France) and all water troughs and feed containers were also thoroughly cleaned and refilled.

Blood Chemistry and Hematology. Blood samples were taken from all calves at 4, 11, and $18 \mathrm{~d}$ of age and when a calf displayed signs of being clinically ill. Blood samples were collected by jugular venipuncture into evacuated tubes that contained sodium fluoride, EDTA, or no anticoagulant (BD Vacutainer, Franklin Lakes, NJ). Blood samples were stored at approximately $4^{\circ} \mathrm{C}$ until they were delivered to the New Zealand Veterinary Pathology (Hamilton, New Zealand) laboratory for analysis. Blood smear slides were performed on a Sysmex XT-2000 iV using veterinary software and Sysmex reagents (Sysmex Corporation, Kobe, Japan) for estimation of total white blood cell, neutrophil, and lymphocyte counts. White blood cell differentials were performed using a standard 100 cell count and the neutrophil-to-lymphocyte ratio was calculated by dividing the percent of neutrophils by the percent of lymphocytes.

Serum haptoglobin concentrations were measured using a commercially available colorimetric kit (PHASE Haptoglobin Assay Cat. No. TP-801; Tridelta Development Limited, Maynooth, County Kildare) in accordance with the manufacturer's instructions (http:// www.trideltaltd.com/haptoglobin-main-page.html). The analytical sensitivity of this assay was $0.005 \mathrm{mg} /$ $\mathrm{mL}$.

Fecal Sampling. Fecal samples were collected manually via gentle palpation of the rectum from any calves that were considered clinically ill and were tested for the presence of Cryptosporidium, rotavirus, coronavirus, and Salmonella. Cryptosporidium was measured using an acid fast stain to visually detect the presence of Cryptosporidium, which could be seen as round bodies measuring 4 to $5 \mu \mathrm{m}$ in diameter and dark red or pink in color. If more lightly stained, the parasites showed internal bodies that were darker blue or brownish in color. The presence of rotavirus and coronavirus were determined using a commercially available ELISA kit (Pourquier ELISA Calves Diarrhea; Institut Pourquier, Montpellier, France). The 5-step, naked eye reading method was conducted in accordance with the manufacturer's instructions (https://www.idexx.co.uk/ en-gb/livestock/livestock-tests/ruminant-tests/idexx -rota-corona-k99-ag-test/). Selective enrichment fecal cultures were used for the detection of Salmonella.

Feeding Behavior. The ACFS (A\&D Reid, Temuka, New Zealand) used an electronic identification system to identify individual animals as they entered the ACFS. Each ACFS had a single teat to deliver whole milk (at approximately $22-25^{\circ} \mathrm{C}$ ) on the following schedule: $2 \mathrm{~L}$, 3 times per day with a minimum 360-min period with 
no milk access between each complete milk feed (as per normal farm practice in New Zealand). If the calf did not consume the whole $2 \mathrm{~L}$ during the visit, they could return at any point to consume the remainder of the allowance. The ACFS recorded the total number of visits, rewarded visits (calf received part or whole milk allowance), unrewarded visits (calf received no milk), and milk volume consumed per visit.

Lying Behavior. Throughout the study period, lying and standing behavior was recorded continuously on all calves using HOBO pendant $\mathrm{G}$ accelerometer data loggers (64k, Onset Computer Corporation, Bourne, $\mathrm{MA}$ ) set at 1-min intervals recording the $\mathrm{Y}$ and $\mathrm{Z}$ axes. The accelerometers were placed in a durable fabric pouch and strapped onto the lateral side of the hind leg above the metatarsophalangeal joint. Accelerometers were placed horizontally on the leg such that the $\mathrm{x}$-axis ran parallel to the ground, pointing in the anterior direction, and the y-axis pointing toward the dorsal plane of the calf. The pouch was held in position using velcro patches, one sewn to the pouch, the other glued (KAMAR, Livestock Improvement Corporation, Hamilton, New Zealand) to the leg of the calf. The pouch was further held in place by a strap around the leg of the calf. Accelerometers were initialized and downloaded using Onset HOBOware Pro software (Onset Computer Corporation, version 3.7.2). The G-force readings were converted into binary values (e.g., lying $=0$, standing $=1$ ), and hourly $(\mathrm{min} / \mathrm{h})$ and daily $(\mathrm{min} / \mathrm{d})$ summaries of lying time and lying bout frequency (number of bouts/d) were calculated in SAS 9.3 (SAS Institute Inc., Cary, NC) using a code designed for this purpose (AWP UBC, 2016) and validated by Bonk et al. (2013) for use in calves.

\section{Automated Assessment of Pain}

At approximately 3 wk of age $(27 \pm 1.5 \mathrm{~d}$ of age, mean $\pm \mathrm{SD}$ ), 51 female Friesian dairy calves (BW = $48.5 \pm 4.76 \mathrm{~kg}$ ) were selected from the 94 healthy animals and allocated to 1 of 5 treatment groups: (1) sham handling (SHAM; $\mathrm{n}=10$ ), (2) cautery disbudding (DB; $\mathrm{n}=11$ ), (3) administration of local anesthetic (LA) and $\mathrm{DB}(\mathbf{L A}+\mathbf{D B} ; \mathrm{n}=11), 4)$ administration of a nonsteroidal anti-inflammatory drug (NSAID) and DB (NSAID+DB; $\mathrm{n}=9$ ), and (5) administration of LA, NSAID, and DB (LA+NSAID+DB; n $=10)$. The combination of pain relief treatments were included to evaluate whether the automated systems were sensitive enough to measure varying degrees of pain. All calves were restrained in a calf crush with a head bail (Front Opening Calf Bail, Te Pari, Oamaru, New Zealand) during treatments. For DB, LA+DB,
$\mathrm{NSAID}+\mathrm{DB}$, and LA+NSAID+DB calves, an electric cautery iron (Quality electric debudder, 230 V, 190 W; Lister GmbH, Lüdenscheid, Germany) was used to remove the calves horn buds. For $\mathrm{LA}+\mathrm{DB}$ and LA+NSAID+DB calves, $3 \mathrm{~mL}$ of local anesthetic $(2 \%$ lignocaine hydrochloride; Lopaine, Ethical Agents Ltd., Auckland, NZ) was injected into the cornual nerve $(3 \mathrm{~mL})$ and 5 injection sites around the base of the horn bud $(0.2 \mathrm{~mL} /$ site $) 5 \mathrm{~min}$ before disbudding. Immediately before disbudding, a needle prick test was used to verify the success of the cornual nerve block. For NSAID+DB- and LA+NSAID+DB-treated calves, meloxicam $(0.5 \mathrm{mg} / \mathrm{kg}$ of BW; Metacam, Boehringer Ingelheim Ltd., Auckland, NZ) was injected subcutaneously 5 min before disbudding. Treatment groups were balanced for age and BW. Feeding and lying behavior were recorded continuously for $24 \mathrm{~h}$ before and $24 \mathrm{~h}$ after administration of treatment, as described above.

\section{Statistical Analysis}

Prior to analysis, all data were assessed for evidence of departures from the assumptions of normality and homogeneity of variance using the univariate procedures of SAS version 9.4 (SAS Inst. Inc.). The residuals from the log-transformed mixed model analysis showed good consistency with the normality assumptions of the model. For the calf health component of our study, data from calves that were identified with NCD were used (see description above). Each calf with NCD was matched with a healthy control from the same pen taking into account sex, breed, birth date, and birth weight. Healthy controls never presented with any symptoms of NCD or other signs of illness or injury during the study period. Day 0 was the day that calves showed signs of NCD and the equivalent day was used for d 0 for control calves. We were interested in behavioral changes leading up to signs of NCD; therefore, we focused on the $5 \mathrm{~d}$ before appearance of NCD. Milk consumption, blood chemistry and hematology data were log-transformed to meet the assumptions of the analysis. Milk consumption and lying (lying times and frequency of lying bouts) behavior data were analyzed using the mixed model procedure of SAS. The model included the fixed effects of treatment (health status: NCD and healthy), day, treatment by day interaction, and the random effects of pen and calf. The model had a repeated structure on time allowing incorporation of heterogeneity of variances across time. For blood chemistry and hematology (cells counts and haptoglobin concentrations) data, only the blood results from d 0 were compared; the model included the fixed effects of treatment (health status: NCD and healthy) and the 
Table 1. Hematology and haptoglobin concentrations of sick calves with neonatal calf diarrhea $(\mathrm{n}=18)$ and healthy control $(\mathrm{n}=18)$ calves at the time of clinical diagnosis

\begin{tabular}{lcccc}
\hline & \multicolumn{2}{c}{ Health status } & & \\
\cline { 2 - 3 } Item & Control & \multirow{2}{*}{ Sick } & \multirow{2}{*}{ SEM } & P-value \\
\hline Total white blood cell count $\left(\times 10^{9} / \mathrm{L}\right)$ & 7.22 & 9.96 & 0.758 & 0.016 \\
Lymphocyte cell counts $\left(\times 10^{9} / \mathrm{L}\right)$ & 3.98 & 4.29 & 0.238 & 0.355 \\
Neutrophil cell counts $\left(\times 10^{9} / \mathrm{L}\right)$ & 2.75 & 4.92 & 0.678 & 0.034 \\
Monocyte cell counts $\left(\times 10^{9} / \mathrm{L}\right)$ & 0.43 & 0.69 & 0.091 & 0.055 \\
Neutrophil-to-lymphocyte ratio & 0.71 & 1.27 & 0.198 & 0.024 \\
Eosinophil cell counts $\left(\times 10^{9} / \mathrm{L}\right)$ & 0.01 & 0.04 & 0.010 & 0.092 \\
Basophil counts $\left(\times 10^{9} / \mathrm{L}\right)$ & 0.07 & 0.05 & 0.018 & 0.401 \\
Haptoglobin $(\mathrm{g} / \mathrm{L})$ & 0.41 & 0.51 & 0.057 & 0.188 \\
\hline
\end{tabular}

random effect of pen. Feeding behaviors (total number of visits, and number of rewarded and unrewarded visits) were analyzed using the GLIMMIX procedure of SAS with a specified Poisson distribution. The model included the fixed effects of treatment (health status: NCD and healthy), day, treatment by day interaction, and the random effects of pen and calf. The model had a repeated structure on time allowing incorporation of heterogeneity of variances across time.

For the analysis of the pain assessment component of this study, milk consumption was log-transformed to meet the assumptions of the analysis. Milk consumption and lying times data were analyzed using the mixed model procedure in SAS and the model included the fixed effects of treatment (SHAM, DB, LA+DB, $\mathrm{NSAID}+\mathrm{DB}, \mathrm{LA}+\mathrm{NSAID}+\mathrm{DB})$, day/time, treatment by day/time interaction, and the random effects of pen and calf. The model had a repeated structure on time allowing incorporation of heterogeneity of variances across time. Lying times were summarized over the entire 24 -h pre- and posttreatment period and analyzed. In addition, hourly lying times for the first $2 \mathrm{~h}$ after administration of treatments were analyzed, as this time period is representative of the cortisol response to cautery disbudding (Graf and Senn, 1999; Stafford and Mellor, 2011). Feeding behaviors (total number of visits and number of rewarded and unrewarded visits) were analyzed using the GLIMMIX procedure of SAS with a specified Poisson distribution. The model included the fixed effects of treatment (SHAM, DB, LA+DB, $\mathrm{NSAID}+\mathrm{DB}, \mathrm{LA}+\mathrm{NSAID}+\mathrm{DB})$, day/time, treatment by day/time interaction, and the random effect of pen. The model had a repeated structure on time allowing incorporation of heterogeneity of variances across time. The sample size was determined by a power analysis with $80 \%$ power and 5\% significance level.

Data displayed in the graphs, tables, and text are actual data summarized by least squares means \pm standard error of the means. Statistical significance was determined at $P \leq 0.05$ and $0.05<P \leq 0.10$ were considered a tendency.

\section{RESULTS}

\section{Automated Assessment of Calf Health}

Fecal Sampling. Four calves tested positive for Cryptosporidium, 1 with rotavirus, 1 with coronavirus, and 1 with Cryptosporidium and rotavirus. No calves tested positive for Salmonella. Eleven calves identified as having NCD according to the criteria (diarrhea and high rectal temperatures) did not test positive for either Cryptosporidium, rotavirus, coronavirus, or Salmonella, so the cause of NCD for these calves was unknown.

Blood Chemistry and Hematology. Total white blood, neutrophil, and monocyte cell counts and the neutrophil-to-lymphocyte ratio were higher $(P \leq 0.055)$ and eosinophil cell counts tended $(P=0.092)$ to be higher in calves with NCD than healthy calves (Table 1 ). Health status of the calves did not affect any other hematology measures or haptoglobin concentrations (Table 1).

Feeding Behavior. Calves with NCD tended $(P$ $=0.079)$ to visit the feeder less than healthy calves over the 5-d period before signs of NCD (total number of visits to the feeder/d: control: $6.7 \pm 0.93$; sick: 4.7 $\pm 0.93)$. We observed no effect of health status $(P=$ $0.506)$ or a health status $\times$ day interaction $(P=0.110)$ for the number of rewarded visits; however, the number of rewarded visits to the feeder changed $(P<0.001)$ over the 5 -d study period (number of rewarded visits to the feeder $/ \mathrm{d}$ : $\mathrm{d}-5=2.8 \pm 0.34 ; \mathrm{d}-4=3.1 \pm 0.35$; $\mathrm{d}-3=3.5 \pm 0.40 ; \mathrm{d}-2=4.2 \pm 0.42 ; \mathrm{d}-1=3.8 \pm$ 0.44 ; d $0=3.4 \pm 0.46)$.

The number of unrewarded visits was affected by health status $(P=0.013)$ and day $(P<0.001$; Figure $1)$. Calves with NCD performed fewer unrewarded visits than healthy calves on $\mathrm{d}-2(P=0.007),-1(P=$ 


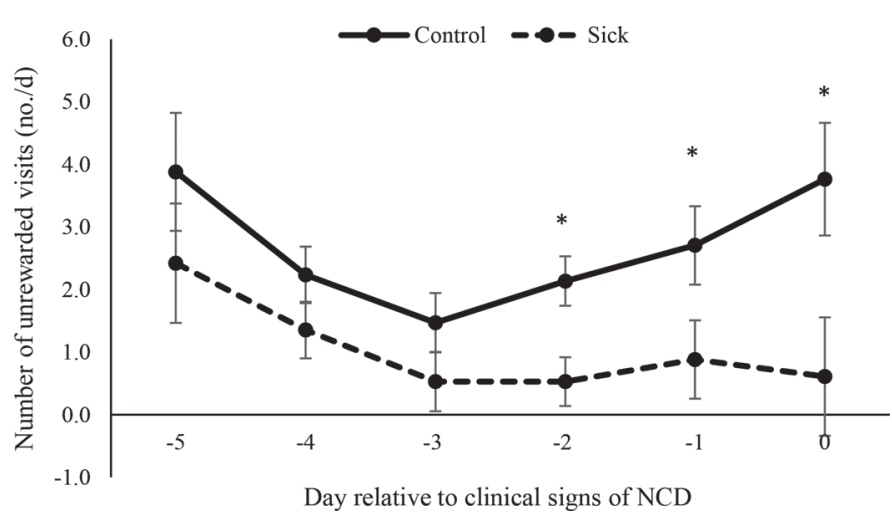

Figure 1. The number of unrewarded visits (no./d: LSM \pm SEM) to the feeder performed by sick calves diagnosed with neonatal calf diarrhea $(\mathrm{NCD} ; \mathrm{n}=18)$ and healthy control matched $(\mathrm{n}=18)$ calves during the $5 \mathrm{~d}$ before showing signs of illness. Means accompanied by an asterisk $\left(^{*}\right)$ differ at $P \leq 0.05$.

$0.055)$, and $0(P=0.025)$. We noted a health status $\times$ day interaction for volume of milk consumed $(P=$ 0.001; Figure 2); calves with NCD drank less on d -4 $(P=0.012),-2(P=0.044),-1(P=0.053)$, and $0(P$ $<0.001)$ than healthy calves.

Lying Behavior. We found a health status $\times$ day interaction for time spent lying $(P=0.014$; Figure 3$)$. Calves with NCD tended to spend more time lying on $\mathrm{d}-2(P=0.08)$ but less time lying on d $0(P=0.085)$. Moreover, calves with NCD tended $(P=0.082)$ to perform fewer lying bouts than healthy calves over the entire 5-d period before diagnosis with NCD (number of lying bouts $/$ d: control $=17.4 \pm 1.16 ;$ sick $=15.8 \pm$ $1.16)$.

\section{Automated Detection of Pain Behavior}

Feeding Behavior. The total number of visits, rewarded visits, unrewarded visits, and milk volume consumed was similar $(P>0.05)$ among all treatments during the 24 -h period before administration of treatments (Table 2). During the 0 to $24 \mathrm{~h}$ posttreatment period, milk volume consumed was similar $(P>0.05)$ among SHAM and disbudded calves, with or without pain relief (Table 2). However, SHAM calves visited the ACFS more during the 24-h posttreatment period than DB $(P<0.006)$ and $\mathrm{LA}+\mathrm{DB}(P<0.002)$ calves, but LA + NSAID + DB visited the feeder a similar $(P=$ 0.186 ) number of times as SHAM calves (Table 2).

We observed no differences $(P>0.05)$ across treatments in the number of rewarded visits to the ACFS (Table 2). However, calves experiencing the SHAM treatment had more unrewarded visits during the $24-\mathrm{h}$ posttreatment period than DB $(P=0.001), \mathrm{LA}+\mathrm{DB}(P$

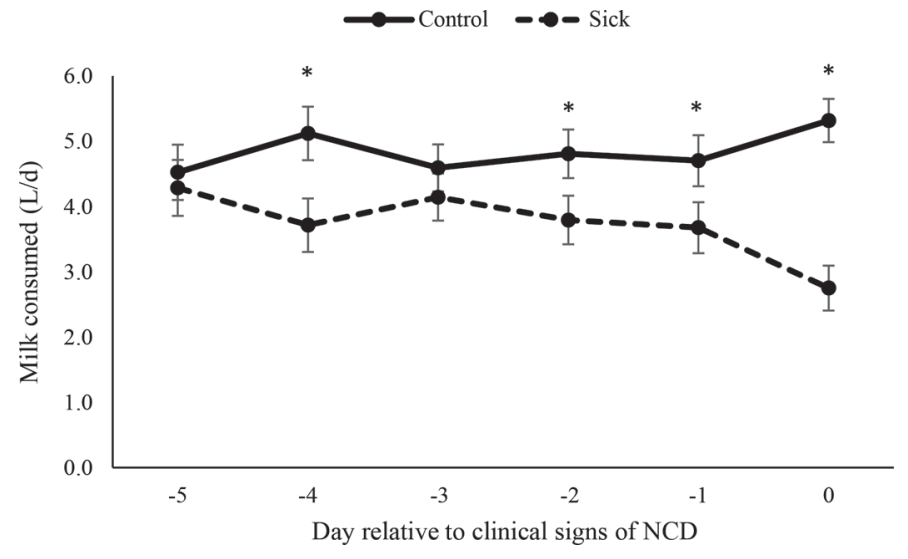

Figure 2. Milk volume (L/d; LSM \pm SEM) consumed by sick calves diagnosed with neonatal calf diarrhea $(\mathrm{NCD} ; \mathrm{n}=18)$ and healthy control matched $(\mathrm{n}=18)$ calves during the $5 \mathrm{~d}$ before showing signs of illness. Means accompanied by an asterisk $\left(^{*}\right)$ differ at $P<0.05$.

$<0.001)$, and NSAID+DB $(P<0.001)$ calves, but the number of unrewarded visits was similar $(P=0.073)$ for SHAM and LA+NSAID+DB calves (Table 2).

Lying Behavior. The proportion of time calves spent lying was similar $(P>0.05)$ among all treatment groups over the 24 -h pre- and 24 -h posttreatment period (Table 2). However, during the 2-h posttreatment period, we found a difference among treatments (Figure 4). During the first hour, DB $(P=0.021)$ and NSAID + DB $(P=0.011)$ calves spent less time lying than SHAM calves. Moreover, lying times were similar $(P>0.570)$ among SHAM, LA+DB, and LA+NSAID+DB calves. Lying times were similar among all treatments during the 2-h posttreatment period.

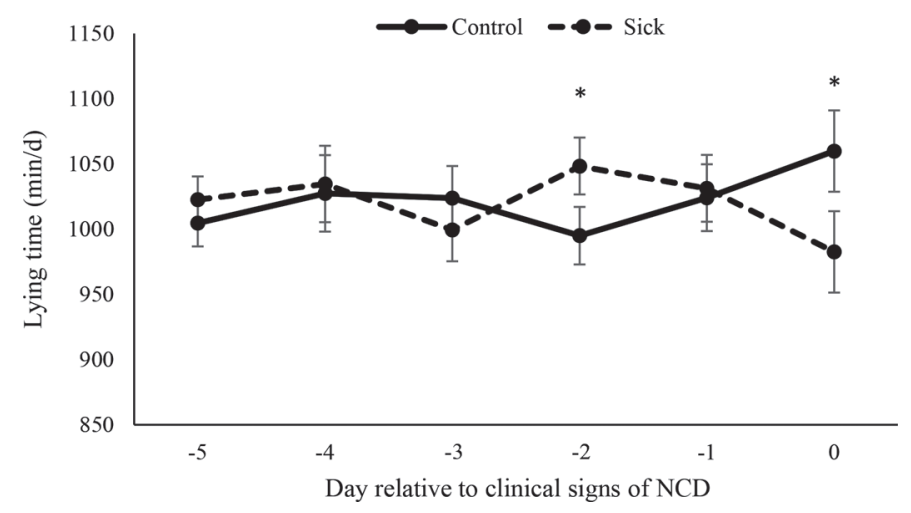

Figure 3. Lying times ( $\mathrm{min} / \mathrm{d}$; LSM $\pm \mathrm{SEM}$ ) of sick calves diagnosed with neonatal calf diarrhea $(\mathrm{NCD} ; \mathrm{n}=18)$ and healthy control matched $(\mathrm{n}=18)$ calves during the $5 \mathrm{~d}$ before showing signs of illness. Means accompanied by an asterisk $\left({ }^{*}\right)$ differ at $P<0.05$. 
Table 2. Feeding and lying behavior of calves pretreatment ( $24 \mathrm{~h}$ immediately preceding the time of treatment) and $24 \mathrm{~h}$ from the time of treatment $(24 \mathrm{~h})$

\begin{tabular}{|c|c|c|c|c|c|c|c|}
\hline \multirow[b]{2}{*}{ Feeding behavior } & \multicolumn{5}{|c|}{ Treatment $^{1}$} & \multirow[b]{2}{*}{ SEM } & \multirow[b]{2}{*}{$P$-value } \\
\hline & SHAM & DB & $\mathrm{LA}+\mathrm{DB}$ & $\mathrm{NSAID}+\mathrm{DB}$ & $\mathrm{LA}+\mathrm{NSAID}+\mathrm{DB}$ & & \\
\hline Pretreatment & 4.35 & 4.95 & 4.65 & 4.77 & 5.00 & 0.603 & 0.612 \\
\hline $24 \mathrm{~h}$ & 6.12 & 5.58 & 5.76 & 5.70 & 6.11 & 0.230 & 0.223 \\
\hline \multicolumn{8}{|l|}{ Total visits (no.) } \\
\hline Pretreatment & 6.40 & 5.73 & 6.64 & 6.66 & 6.29 & 1.878 & 0.907 \\
\hline Pretreatment & 2.39 & 3.09 & 3.72 & 3.51 & 2.76 & 0.731 & 0.418 \\
\hline $24 \mathrm{~h}$ & 3.40 & 3.00 & 3.09 & 4.11 & 3.40 & 0.357 & 0.707 \\
\hline \multicolumn{8}{|c|}{ Unrewarded visits (no.) } \\
\hline Pretreatment & 3.94 & 2.61 & 2.88 & 3.10 & 3.52 & 1.442 & 0.418 \\
\hline $24 \mathrm{~h}$ & $4.93^{\mathrm{a}}$ & $2.10^{\mathrm{bc}}$ & $1.47^{\mathrm{c}}$ & $1.98^{\mathrm{bc}}$ & $3.37^{\mathrm{ab}}$ & 0.879 & 0.001 \\
\hline \multicolumn{8}{|c|}{ Time spent lying (\%) } \\
\hline Pretreatment & 42.4 & 40.7 & 41.8 & 38.2 & 40.6 & 1.46 & 0.127 \\
\hline
\end{tabular}

${ }^{\mathrm{a}-\mathrm{c}}$ Means within each row with different superscripts differ at $P<0.05$.

${ }^{1}$ Sham handling (SHAM; $\left.\mathrm{n}=10\right)$, cautery disbudding $(\mathrm{DB} ; \mathrm{n}=11)$, administration of local anesthetic $+\mathrm{DB}(\mathrm{LA}+\mathrm{DB} ; \mathrm{n}=11)$, administration of a nonsteroidal anti-inflammatory drug (NSAID) + DB (NSAID+DB; $\mathrm{n}=9)$, and LA+NSAID+DB $(\mathrm{n}=10)$.

\section{DISCUSSION}

Feeding and lying behaviors collected using ACFS and accelerometers were affected by health status and pain in calves in the present study. The number of unrewarded visits declined before calves showed signs of NCD. Differences in the number of unrewarded visits was apparent $2 \mathrm{~d}$ before calves showed signs of NCD; however, we found no change in the number of rewarded visits before diagnosis. Similarly, Svensson and Jensen (2007) found that the number of unrewarded visits was a more sensitive measure of sickness in calves than the number of rewarded visits. Borderas et al.

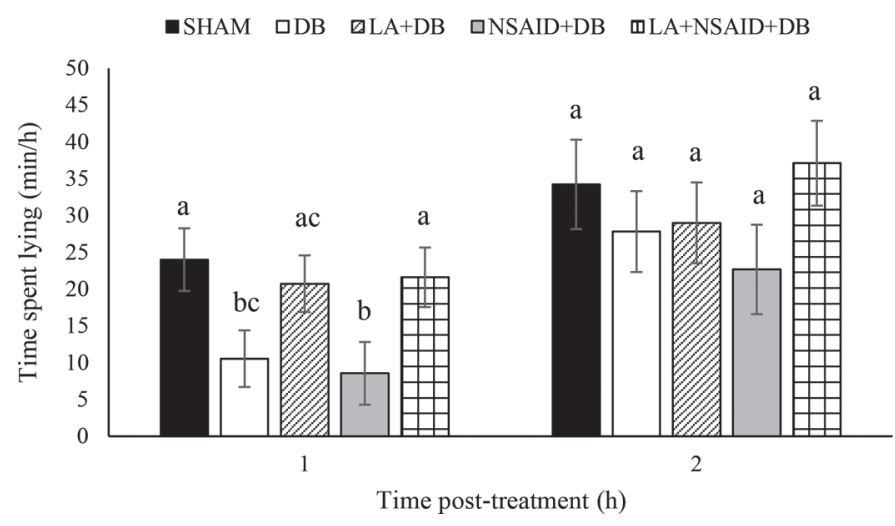

Figure 4. Lying times $(\mathrm{min} / \mathrm{h} ; \mathrm{LSM} \pm \mathrm{SEM})$ of calves during the first $2 \mathrm{~h}$ after disbudding or control handling. Treatments were sham handling (SHAM; $\mathrm{n}=10$ ), cautery disbudding (DB; $\mathrm{n}=11)$, administration of local anesthetic $+\mathrm{DB}(\mathrm{LA}+\mathrm{DB} ; \mathrm{n}=11)$, administration of a nonsteroidal anti-inflammatory drug (NSAID) + DB (NSAID+DB; $\mathrm{n}=9)$, and $\mathrm{LA}+\mathrm{NSAID}+\mathrm{DB}(\mathrm{n}=10)$. Means within each hour with different letters $(\mathrm{a}-\mathrm{c})$ differ at $P<0.05$.
(2009) suggested that the effect of disease on feeding behavior would vary according to feeding motivation, as milk intake and frequency of visits to the feeder were more dramatically decreased in sick calves being fed a high (ad libitum or $12 \mathrm{~L} / \mathrm{d}$ ) rather than a low $(4 \mathrm{~L} / \mathrm{d}$ ) milk allowance. In the present study, calves received a milk allowance of $6 \mathrm{~L} / \mathrm{d}$, which is closer to the low than the high milk allowance provided in the Borderas et al. (2009) study; hence, more dramatic changes in feeding behavior may have been observed if a higher milk allowance was provided to calves in the present study. Therefore, milk allowance fed to calves needs to be taken into consideration when using behavioral data from ACFS as an indication of NCD in calves.

Contrary to other studies (Svensson and Jensen, 2007; Borderas et al., 2009; Lowe et al., 2016), milk consumption was reduced in sick calves up to $4 \mathrm{~d}$ before displaying signs of NCD in the present study. Hence, milk consumption in combination with the number of unrewarded visits maybe a good measure for early detection of NCD in calves. Differences in feeding behavior among studies may relate to the pathogenesis of the disease. In other studies, calves were diagnosed with a range of illnesses, including gastrointestinal, respiratory, or a combination of these diseases (Borderas et al., 2009; Swartz et al., 2017), or other signs of disease such as arthritis, fever, dull calf syndrome, and so on (Svensson and Jensen, 2007). However, in those studies, samples were not taken to verify the pathogenesis of the diseases. In our study, only calves that were diagnosed as having NCD were used; however, even with fecal sampling we could only confirm the cause of NCD in 7 out of 18 calves. Therefore, due to the 
differences in the pathogenesis affecting calves among our study and previous studies, it is difficult to know the reason for the difference in results. In addition to pathogenesis, age of calves at the time of diagnosis, severity of outbreak, and the time of diagnosis could potentially affect feeding and lying behavior in calves. Further research focused on particular pathogens or disease severity would be of interest to assist in our understanding of the relationship between pathogenesis and sickness behavior in calves.

Calves challenged with a low dose of bacterial endotoxin spent more time lying and performed fewer standing bouts in Borderas et al. (2008), similar to the present study, and sick calves spent more time lying 2 $\mathrm{d}$ before displaying clinical signs of NCD and tended to perform fewer lying bouts. A reduction in activity of sick calves may be part of the adaptive strategy adopted by mammals to help combat infections (Hart, 1988). However, on the day calves were diagnosed as having NCD in the present study their lying times were reduced. At the time calves were diagnosed with NCD, blood and fecal samples were collected and animals were moved to the sick pen and treated with electrolytes; this extra handling may account for the reduction in lying times.

In the present study, disbudding treatment affected the total number of visits that calves made to the feeder during the 24-h posttreatment period. This difference was predominantly due to the number of unrewarded visits as disbudding treatment did not affect the number of rewarded visits. Calves experiencing the SHAM treatment performed more unrewarded visits during the 24 -h posttreatment period than $\mathrm{DB}, \mathrm{LA}+\mathrm{DB}$, and NSAID+DB calves. The greater number of unrewarded visits suggests that even though there was no difference in the amount of milk consumed among treatments, calves that were not disbudded were more motivated to visit the ACFS than calves disbudded with LA or NSAID or without pain relief. Fewer unrewarded visits to the ACFS by disbudded calves could reflect a lack of appetite in these animals due to the pain or distress caused by disbudding. Indeed, calves spent less time feeding after cautery disbudding (Graf and Senn, 1999) and amputation dehorning (Sutherland et al., 2013). It is also possible that disbudding caused the calves in the present study to become head shy and, hence, more hesitant to place their heads in the ACFS due to the potential risk of knocking their head in the confined space. Another possibility is that experiencing a painful husbandry procedure caused a change in the emotional state of the animals, which may in turn have affected their motivation to feed (Neave et al., 2013). Interestingly, calves given local anesthetic and an NSAID before disbudding in the present study per- formed a similar number of unrewarded visits as SHAM calves, which suggests that the combination of LA and an NSAID was the most effective pain-mitigation strategy evaluated in the present study. These results are in accordance with previous studies showing that the physiological and behavioral response to disbudding is markedly reduced when calves are given a combination of LA and an NSAID before disbudding (Duffield et al., 2010; Heinrich et al., 2010).

Total milk consumption was not affected by disbudding, with or without pain relief, in the present study. In contrast, Bates et al. (2015) found that when calves were given the same milk allowance as provided in the present study $(6 \mathrm{~L} / \mathrm{d})$, mean cumulative milk consumption over the 11-d postdisbudding period was greater for calves disbudded with pain relief compared with those without. Therefore, it is possible that if milk consumption had been recorded for a longer period of time in the present study, treatment differences may have been detected. Furthermore, milk allowance is an important factor to consider when using total milk consumption as an indicator of stress (e.g., pain or disease). Borderas et al. (2009) found that sick calves consumed less milk at an ACFS when provided with a high milk allowance in comparison to healthy calves, but total milk consumption was not affected when they were provided with a low milk allowance. Calves provided only a low milk allowance are more likely to be motivated to feed. In the present study, calves were given access to $6 \mathrm{~L} / \mathrm{d}$, whereas calves given ad libitum access to milk will drink up to $10 \mathrm{~kg} / \mathrm{d}$ (Jasper and Weary, 2002). Therefore, providing calves with a higher milk allowance is likely to increase the sensitivity of feeding behavior as a measure of stress (e.g., pain and disease) in calves.

The proportion of time disbudded calves spent lying was similar across all treatments groups over the entire 24-h posttreatment period in the present study; however, during the 2-h period after disbudding, treatment affected lying behavior. During the first hour after disbudding, calves given local anesthetic showed similar lying patterns to control-handled calves, which is similar to the results reported by McMeekan et al. (1999) $2 \mathrm{~h}$ after amputation dehorning. These findings may suggest that calves given local anesthetic were experiencing less pain initially than calves disbudded without pain relief. Moreover, calves given only an NSAID before disbudding showed similar lying times to calves disbudded without pain relief, which corresponds to the mechanism of action of NSAID; giving an NSAID (e.g., ketoprofen) reduces the inflammation-related pain associated with amputation dehorning in cattle, but not the initial pain caused by dehorning (McMeekan et al., 1998). These results suggest that lying behavior mea- 
sured using accelerometer data loggers maybe sensitive enough to assess pain in calves in response to an acute painful procedure such as cautery disbudding.

In conclusion, automated measures of feeding and lying behavior could be used to detect changes in behavior before the onset of clinical signs of NCD or in response to acute pain in calves. The number of unrewarded visits to the ACFS appeared to be a more sensitive measure of NCD and pain in calves than automated measures of lying behavior. It would be of interest to confirm these results using animals exposed to different conditions (e.g., different pathogens) or other painful procedures (e.g., castration, lameness).

\section{ACKNOWLEDGMENTS}

The authors thank AgResearch staff, in particular Suzanne Dowling, Tokanui farm staff (South Waikato, New Zealand), Theresa Topp from Waikato University, and Alvin Reid (A\&D Reid, Temuka, New Zealand) for providing the automatic calf feeders. AgResearch also gratefully acknowledges that this study was funded by the New Zealand Ministry of Business, Innovation and Employment (Wellington, New Zealand).

\section{REFERENCES}

AWP UBC (Animal Welfare Program, University of British Columbia). 2016. UBC Animal Welfare Program: SOP - HOBO Data Loggers, SAS CODE Version 1. University of British Columbia, Vancouver, BC, Canada.

Bates, A. J., P. Eder, and R. Laven. 2015. Effect of analgesia and antiinflammatory treatment on weight gain and milk intake of dairy calves after disbudding. N. Z. Vet. J. 63:153-157.

Bonk, S., O. Burfeind, V. S. Suthar, and W. Heuwieser. 2013. Technical note: Evaluation of data loggers for measuring lying behavior in dairy calves. J. Dairy Sci. 96:3265-3271. https://doi.org/10 $.3168 /$ jds.2012-6003.

Borderas, T. F., A. M. de Pasille, and J. Rushen. 2008. Behaviour of dairy calves after a low dose of bacterial endotoxin. J. Anim. Sci. 86:2920-2927.

Borderas, T. F., J. Rushen, M. A. G. von Keyserlingk, and A. M. de Pasille. 2009. Automated measurement of changes in feeding behaviour of milk fed calves associated with illness. J. Dairy Sci. 92:4549-4554.

Duffield, T. F., A. Heinrich, S. T. Millman, A. DeHaan, S. James, and K. Lissemore. 2010. Reduction in pain response by combined use of local anesthesia and systemic ketoprofen in dairy calves dehorned by heat cauterization. Can. Vet. J. 51:283-288.

Faulkner, P. M., and D. M. Weary. 2000. Reducing pain after dehorning in calves. J. Dairy Sci. 83:2037-2041.
Graf, B., and M. Senn. 1999. Behavioural and physiological responses of calves to dehorning by heat cauterization with or without local anaesthesia. Appl. Anim. Behav. Sci. 62:153-171.

Hart, B. L. 1988. Biological basis of the behavior of sick animals. Neurosci. Biobehav. Rev. 12:123-137.

Heinrich, A., T. F. Duffield, K. D. Lissemore, and S. T. Millman. 2010 The effect of meloxicam on behavior and pain sensitivity of dairy calves following cautery dehorning with a local anesthetic. J. Dairy Sci. 93:2450-2457. https://doi.org/10.3168/jds.2009-2813.

Jasper, J., and D. M. Weary. 2002. Effects of ad libitum milk intake on dairy calves. J. Dairy Sci. 85:3054-3058.

Lowe, G., A. L. Schaefer, J. R. Waas, M. T. Wilson, M. A. Sutherland, and M. Stewart. 2016. Brief communicatION: The use of infrared thermography and feeding behaviour for early disease detection in New Zealand dairy calves. Proc. N.Z. Soc. Anim. Prod. 76:177-179.

McMeekan, C. M., K. J. Stafford, D. J. Mellor, R. A. Bruce, R. N. Ward, and N. Gregory. 1998. Effects of regional analgesia and/or a non-steroidal anti-inflammatory analgesic on the acute cortisol response to dehorning in calves. Res. Vet. Sci. 64:147-150.

McMeekan, C., K. J. Stafford, D. J. Mellor, R. A. Bruce, R. N. Ward, and N. G. Gregory. 1999. Effects of a local anaesthetic and a nonsteroidal anti-inflammatory analgesic on the behavioural responses of calves to dehorning. N. Z. Vet. J. 47:92-96.

Ministry of Primary Industries. 2017. Animal Welfare Act 1999. Accessed Jun. 6, 2018. http://www.legislation.govt.nz/act/public/ 1999/0142/56.0/DLM49664.html.

Neave, H. W., R. R. Doras, J. H. C. Costas, M. A. G. von Keyserlingk, and D. M. Weary. 2013. Pain and pessimism: Dairy calves exhibit negative judgement bias following hot-iron disbudding. PLoS One 8:e80556. https://doi.org/10.1371/journal.pone.0080556.

Schroeder, M. E., M. A. Bounpheng, S. Rodgers, R. J. Baker, W Black, H. Naikare, B. Velayudhan, L. Sneed, B. Szonyi, and A. Clavijo. 2012. Development and performance evaluation of calf diarrhoea pathogen nucleic acid purification and detection workflow. J. Vet. Diagn. Invest. 24:945-953.

Stafford, K., and D. Mellor. 2011. Addressing the pain associated with disbudding and dehorning in cattle. Appl. Anim. Behav. Sci. 135:226-231.

Sutherland, M. A., M. A. Ballou, B. L. Davis, and T. A. Brooks. 2013. Effect of castration and dehorning singularly or combined on the behavior and physiology of Holstein calves. J. Anim. Sci. 91:935-942. https://doi.org/10.2527/jas.2012-5190.

Svensson, C., and M. B. Jensen. 2007. Identification of diseased calves by use of data from automatic milk feeders. J. Dairy Sci. 90:994997.

Swartz, T. H., A. N. Findlay, and C. S. Petersson-Wolfe. 2017. Short communication: Automated detection of behavioral changes from respiratory disease in pre-weaned calves. J. Dairy Sci. 100:92739278.

Szyszka, O., and I. Kyriazakis. 2013. What is the relationship between level of infection and 'sickness behaviour' in cattle. Appl. Anim. Behav. Sci. 147:1-10.

USDA. 2018. Dairy 2014, Report 3: Health and Management Practices on U.S. Dairy Operations, 2014. No. 696.0218. USDA-Animal and Plant Health Inspection Service (APHIS)-Veterinary Services (VS)-Center for Epidemiology and Animal Health (CEAH)-National Animal Health Monitoring System (NAHMS), Fort Collins, CO. Accessed Mar. 1, 2018. https://www.aphis.usda.gov/animal _health/nahms/dairy/downloads/dairy14/Dairy14_dr_PartIII .pdf. 